\title{
Comparing desferrioxamine and light fractionation enhancement of ALA-PpIX photodynamic therapy in skin cancer
}

\author{
Ana Luiza Ribeiro de Souza ${ }^{1,2}$, Kayla Marra ${ }^{1}$, Jason Gunn ${ }^{1}$, Kimberley S Samkoe ${ }^{1,3}$, Stephen Chad Kanick ${ }^{1}$, \\ Scott C Davis ${ }^{1}$, M Shane Chapman ${ }^{3}$, Edward V Maytin ${ }^{4}$, Tayyaba Hasan ${ }^{5}$ and Brian W Pogue ${ }^{\star 1,3}$ \\ ${ }^{1}$ Thayer School of Engineering, Dartmouth College, Hanover, NH 03755, USA; ${ }^{2}$ CAPES Foundation, Ministry of Education of Brazil, \\ Brasilia 70040-020, Brazil; ${ }^{3}$ Department of Surgery, Geisel School of Medicine, Dartmouth College, Lebanon, NH 03756, USA; \\ ${ }^{4}$ Department of Biomedical Engineering, Cleveland Clinic, Cleveland, OH 44195, USA and ${ }^{5}$ Wellman Center for Photomedicine, \\ Massachusetts General Hospital, Harvard Medical School, Boston, MA 02114, USA
}

Background: Aminolevulinic acid (ALA)-based photodynamic therapy (PDT) provides selective uptake and conversion of ALA into protoporphyrin IX (PpIX) in actinic keratosis and squamous cell carcinoma, yet large response variations in effect are common between individuals. The aim of this study was to compare pre-treatment strategies that increase the therapeutic effect, including fractionated light delivery during PDT (FPDT) and use of iron chelator desferrioxamine (DFO), separately and combined.

Methods: Optical measurements of fluorescence were used to quantify PpIX produced, and the total amount of PpIX photobleached as an implicit measure of the photodynamic dose. In addition, measurements of white light reflectance were used to quantify changes in vascular physiology throughout the PDT treatment.

Results: fPDT produced both a replenishment of PpIX and vascular re-oxygenation during a $2 \mathrm{~h}$ dark interval between the first and second PDT light fractions. The absolute photodynamic dose was increased $57 \%$ by fPDT, DFO and their combination, as compared with PDT group (from 0.7 to 1.1). Despite that light fractionation increased oedema and scab formation during the week after treatment, no significant difference in long-term survival has been observed between treatment groups. However, outcomes stratified on the basis of measured photodynamic dose showed a significant difference in long-term survival.

Conclusions: The assessment of implicit photodynamic dose was a more significant predictor of efficacy for ALA-PDT skin cancer treatments than prescription of an enhanced treatment strategy, likely because of high individual variation in response between subjects.

Photodynamic therapy (PDT) involves the use of light to activate a photosensitizer, resulting in the formation of reactive oxygen species (ROS) that initiate oxidative stress, inflammation and cellular death in diseased tissues (Kennedy et al, 1990; Dougherty et al, 1998; Braathen et al, 2007; Celli et al, 2010; Bovis et al, 2012). Significant improvements in the ability to target skin lesions with PDT have been shown in the past decade, with wider clinical acceptance and FDA approval of treatment for actinic keratosis (AK; Redbord and Hanke, 2007; Palm and Goldman,
2011). In this study, enhancement of the PDT effect was examined with two adjuvant treatments which are known to increase efficacy.

The type of PDT used here was with aminolevulinic acid (ALA), known as a prodrug that is converted to protoporphyrin IX (PpIX) in the haem synthesis pathway of cells. PpIX is an endogenous photosensitizer, which is believed to be produced preferentially in cancer cells due to the high metabolic activity from excess mitotic activity (Kennedy et al, 1990; Kennedy and

*Correspondence: Professor BW Pogue; E-mail: brian.w.pogue@dartmouth.edu

Received 29 April 2016; revised 15 July 2016; accepted 26 July 2016; published online 30 August 2016

(c) 2016 Cancer Research UK. All rights reserved 0007 - 0920/16 
Pottier, 1992; Ibbotson, 2010). In dermatological use, the fact that ALA is a hydrophilic molecule (Cairnduff et al, 1994) and is passively diffused across the stratum corneum is used as the delivery methodology, allowing cellular production of PpIX in areas where ALA is topically applied (Di Venosa et al, 2006). However, this diffusion process reduces its effectiveness in the treatment of deep lesions such as nodular basal cell carcinomas or any lesions with overlying keratin debris (Cairnduff et al, 1994; Morton et al, 1998). These factors can introduce substantial variability in the amount of PpIX generated in lesions prior to treatment (Kanick et al, 2015).

In order to increase the success rate of ALA-PDT in large and deep tumours, strategies have been developed and are described in the literature in order to overcome some obstacles of topical ALA-PDT (Fang et al, 2008; Anand et al, 2009; Araújo et al, 2010; Maytin et al, 2012). The use of some metal chelators, such as ethylenediaminetetraacetic acid, desferrioxamine (DFO) and 1,2-diethyl-3-hydroxypyridin-4-one hydrochloride (CP94), have been studied as inhibitors of ferrochelatase activity-the enzyme responsible for conversion of PpIX into haem molecules. As this process is iron-dependent, PpIX would not be converted to haem and, consequently, it would increase PpIX available in the tumour cells (Hanania and Malik, 1992; Pye and Curnow, 2007). In a study performed by Chang et al (1997), the administration of CP94 was able to double the production of PpIX in urothelium of rats after administration of $10 \%$ of ALA, whereas no increase in PpIX production was observed in the muscle layer. Valdes et al (2010) found that the administration of DFO resulted in a $50 \%$ increase of the mean PpIX fluorescence contrast in a glioma mice model.

A different approach to enhance the efficacy of ALA-PDT is the fractionation of the light dose administered during PDT (fPDT; Robinson et al, 2000; de Bruijn et al, 2006, 2013). Research has recently shown that administration of light with an intermittent dark period between light delivery enhanced the response of superficial basal cell carcinoma to ALA-PDT significantly (de Haas et al, 2006; Star et al, 2006). The mechanism in this case is thought to be increased blood flow and replenishment of PpIX which had been photobleached, to produce a second round of PDT damage in the second light fraction.

These two methods have been studied separately, but never together in the same tumour lines, and the combined results could be promising to enhance the PpIX production together. A preliminary study by Curnow et al (2006) studied the use of CP94 combined with light dose fractionation in normal colon and their results showed an increase in necrosis volume when iron chelator and fractionated PDT was used. However, there has never been a study using these two approaches in cancer in vivo. The primary aim of the present study was to use the dosimetry to evaluate, in squamous cell carcinoma (SCC) tumour-bearing mice, the individual and combinatorial effects of iron chelation and light fractionation on PpIX-PDT treatment outcome. A secondary aim was to optically quantitate the amount of PpIX consumed during the photodynamic reaction for use as a surrogate metric of the delivered therapeutic dose that was compared with treatment outcome.

\section{MATERIALS AND METHODS}

Chemicals. 5-Aminolevulinic acid hydrochloride and DFO mesylate were purchased from Sigma-Aldrich (St Louis, MO, USA). Levulan Kerastick (ALA for topical solution, 20\%) was obtained from DUSA Pharmaceuticals (Wilmington, MA, USA).

Cell experiments. All cell lines were obtained from ATCC (Manassas, VA, USA) and grown as described. SCC9 (ATCC
CRL-1629), SCC15 (ATCC CRL-1623) and SCC25 (ATCC CRL1628) were derived from human SCC of the tongue, A431 (ATCC CRL-1555) cells were from human epidermoid carcinoma of the skin/epidermis and FaDu (ATCC HTB-43) cells came from human squamous carcinoma from pharynx. Culture was performed in the presence in $10 \%$ fetal bovine serum (FBS) and penicillinstreptomycin at $37{ }^{\circ} \mathrm{C}$ and $5 \% \mathrm{CO}_{2}$ in a humid environment. The purpose of the cell studies was to determine which cell lines benefited the most from iron chelation in terms of PpIX production.

Concentration dependence of PpIX production. The influence of concentration-dependent saturation of PpIX biosynthesis was measured by the incubation of the different cell lines using different concentrations of ALA (0.05-1.0 mM) dissolved in culture medium without FBS. Fluorescence from PpIX was imaged on the Typhoon 9410 Variable Mode Imager (GE Healthcare, Milwaukee, WI, USA) at 50 micron resolution ( $633 \mathrm{~nm}$ excitation laser and $650 \mathrm{~nm}$ long-pass emission filter) after an incubation period of $3 \mathrm{~h}$. During this time, cells sub-cultured in 24-well dishes were incubated in the dark in a $5 \% \mathrm{CO}_{2}$ incubator at $37^{\circ} \mathrm{C}$. Each test plate contained control cells incubated with just culture medium, which were used to remove background fluorescence (Equation 1). All experiments were performed in quadruplicate.

$$
\operatorname{PpIX} F L_{\text {norm }}(\text { a.u. })=\overline{F L}_{A L A}-\overline{F L}_{\text {blank }}
$$

where $\overline{F L}_{A L A}$ and $\overline{F L}_{\text {blank }}$ is the mean of fluorescence obtained from the cells incubated with ALA or medium, respectively.

Influence of DFO mesylate in the PpIX production. To determine the influence of iron chelator on the PpIX production, cells seeded in 24-well plates were incubated using three different concentrations of ALA $(0.05,0.1$, or $0.2 \mathrm{mM})$ with $150 \mu \mathrm{M}$ of DFO mesylate (Pye and Curnow, 2007) or no DFO. Fluorescence from PpIX was imaged as described in Section 2.2.1. The experiment was performed in quadruplicate and repeated three times.

Tumour implantation. All experimental protocols were approved by Dartmouth College Animal Care and Use Committee (IACUC). Intradermal implantation of $1 \times 10^{6}$ cells of SCC25 cells was performed on 50 female nude mice aged 6-8 weeks in the right posterior flank of the mice. When tumours reached $10-20 \mathrm{~mm}^{3}$ volume, tumour-bearing mice were randomly placed in each of the treatment groups: untreated control (no ALA and no PDT), ALA-PDT, ALA-PDT plus intraperitoneal DFO mesylate, ALA-fPDT, and ALA-fPDT plus intraperitoneal DFO mesylate. $10 \mu \mathrm{l}$ of Levulan Kerastick (20\% of ALA) solution was applied topically to the tumour. After $3 \mathrm{~h}$, the remaining ALA was washed off before light treatment, except for the control group that did not receive any treatment. The DFO groups received $200 \mathrm{mg} \mathrm{kg}^{-1}$ of DFO mesylate dissolved in $200 \mu \mathrm{l}$ of PBS administered intraperitoneally for 3 consecutive days before ALA application (Valdes et al, 2010).

The tumour volume was measured using calipers and calculated using the following formula (Peng et al, 2001; Lee et al, 2003),

$$
V=\left(\frac{\pi}{6}\right) \times\left(D_{1} \times D_{2} \times D_{3}\right)
$$

where $D_{1}, D_{2}$, and $D_{3}$ are three orthogonal diameters of the tumours.

Illumination scheme. The light source used in this study was a $635 \mathrm{~nm}$ diode laser with output power of $1 \mathrm{~W}$ (Power Technology, Alexander, AR, USA). The lesions were illuminated at a constant measured fluence rate of $50 \mathrm{~mW} \mathrm{~cm}^{-2}$ calibrated using a powermeter (Thorlabs, Newton, NJ, USA). In the single-illumination group (ALA-PDT), lesions were illuminated $3 \mathrm{~h}$ after ALA application with a total fluence of $50 \mathrm{~J} \mathrm{~cm}^{-2}$. In the twofoldillumination groups (ALA-fPDT), lesions received light fractions of 
10 and $40 \mathrm{~J} \mathrm{~cm}^{-2}, 3$ and $5 \mathrm{~h}$ after ALA application, with mice housed in a dark environment for $2 \mathrm{~h}$ between the two sequential illuminations; Levulan Kerastick (Wilmington, MA, USA) was not reapplied during the dark period. During treatment the mice were anaesthetised with isofluorane and placed on a heated pad to maintain body temperature.

PDT dosimetry measurements. Optical measurements in this study were acquired with the white light source and $405 \mathrm{~nm}$ blue laser diode at three time points during ALA-PDT. (1) Prior to administration of ALA, (2) following $3 \mathrm{~h}$ of incubation with ALA and before light illumination and (3) immediately following administration of the treatment light dose. For ALA-fPDT groups, the optical measurements were performed at five time points.

(1) Prior to ALA application, (2) following $3 \mathrm{~h}$ of incubation with ALA and before first light illumination, (3) immediately following administration of the first light dose, (4) following $2 \mathrm{~h}$ dark interval after first light illumination and before second light illumination, and (5) immediately following administration of the second light dose. All measurements were recorded with the probe tip in gentle contact with the surface of the tumours. Fluorescence emission spectra were analysed by correcting for background optical property distortions and spectrally fit to quantitate PpIX contribution to fluorescence (Kanick et al, 2014). White light spectra were analysed to return the total blood volume fraction (BVF) and microvascular oxygen saturation (Kanick et al, 2014).

The absolute photodynamic dose, which is given in dimensionless units, is estimated by assuming all of the bleached PpIX contributed to the delivered dose, and so the difference in pretreatment $v s$ post-treatment measures of PpIX is a direct proportionality to the delivered dose (Kanick et al, 2014):

$$
\text { Dose }_{P p I X}=c_{P p I X}(\text { PreTX })-c_{P p X I}(\text { PosTX })
$$

For fractionated treatments, this equation was applied to both first and second light-illumination period and the total dose was given as the sum of both.

Oedema and scab formation. In order to evaluate the effect of treatment in oedema formation, the total volume in the region of skin that received light treatment, including both oedema and tumour, was measured during the first week of treatment. The presence of scab during this time was also evaluated.

Response and follow-up. All mice were followed for a period of up to 90 days, measuring tumour volumes throughout this time. When tumours grew to the end point of 10 times of the volume on the day of treatment, the mice were killed by cervical dislocation under anaesthesia.

Statistical analysis. The data distribution normality was evaluated according to the Shapiro-Wilk's test. A parametric two-sample Student's $t$-test (state two tail and equal/unequal variance) was applied to compare groups with normal distribution. For the analysis of non-normally distributed groups, either Wilcoxon (used in in vitro experiments) or Kruskal-Wallis (used in in vivo experiments) were performed. Kaplan-Meier analysis was performed to compare the differences between treatment groups. All analysis were performed with OriginPro 8 software (Northampton, MA, USA). In all statistical tests, a $P$-value of 0.05 or less was considered statistically significant.

\section{RESULTS}

In vitro effect of ALA concentration in PpIX production. The influence of ALA concentration on the PpIX production by different cell lines was evaluated by measuring the intensity of

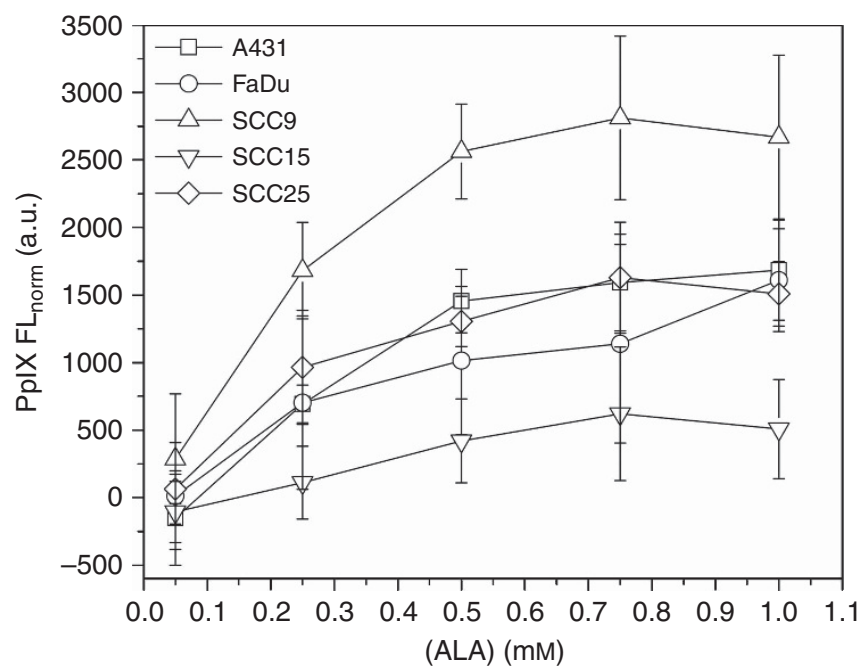

Figure 1. PpIX production for five different cell lines after incubation with ALA. Fluorescence was normalised by auto-fluorescence obtained from the cells incubated with medium (blank).

PpIX fluorescence (Figure 1). The data showed that all cell lines produced PpIX in a dose-dependent manner until it reached a moderate plateau, except for SCC15, which presented no difference in the range of ALA concentration studied. However, the end of the linear part of these curves, as well as the height of the plateau, were dependent on the cell line used. The optimal concentration $\left(c_{\text {opt }}\right)$ was achieved by treating the SCC25 and FaDu with $0.25 \mathrm{~mm}$ of ALA, whereas $0.5 \mathrm{~mm}$ of ALA was necessary by A431 and SCC9 to obtain the maximum PpIX formation.

Effect of iron chelator in PpIX production. In order to evaluate the effect of DFO on PpIX accumulation, three different concentrations of ALA lower than $c_{\mathrm{opt}}$ were selected to prevent saturation provoked by drug itself. As seen from Table 1, PpIX production by $\mathrm{FaDu}$ was not influenced by $\mathrm{DFO}$ treatment ( $P$-value $>0.05$ for all ALA concentrations). For all other cell lines, an increase of PpIX formation after incubation of DFO with ALA was observed, except for SCC9 at the concentration of $0.1 \mathrm{~mm}$ of ALA. Moreover, SCC25 was the cell line that presented an increase of PpIX production of 1.2- to 1.5-fold after incubation with iron chelator and ALA, whereas A431 and SCC15 cells presented $13-20 \%$ and $19-30 \%$ increases in PpIX formation, respectively, depending of the ALA concentration.

In vivo effect of ALA-induced PpIX in skin tumour-bearing nude mice. The results are shown for: (i) PpIX fluorescence (blue excitation), (ii) fitted values of BVF and (iii) oxygen saturation; all graphically presented in Figure 2, for the animals treated with ALA-PDT, iron chelator, PDT fractionated (fPDT) or iron chelator combined with $\mathrm{PPDT}$ and the group control. It can be observed that the pre-treatment of the mice with iron chelator significantly enhanced the PpIX production in the tumour tissue before the illumination treatment, as compared with the animals that did not receive DFO ( $P$-value $<0.05$, two-sample $t$-test); however, there was no significant difference in the PpIX fluorescence before the second illumination between the fPDT and $\mathrm{DFO}+\mathrm{fPDT}$ groups ( $P$-value $>0.05$, two-sample $t$-test). Moreover, the depletion of oxygen during PDT could be observed, which is likely due to reduced blood flow in the treated areas. On the other hand, it is known that PpIX is re-synthesised and tissue oxygenation and blood flow can be replenished during the $2 \mathrm{~h}$ dark interval, for the groups that received fractionated PDT treatment scheme. No change in BVF was observed during or after therapy, nor between treatment groups. 
Table 1. Influence of DFO in PpIX production

\begin{tabular}{|c|c|c|c|c|c|c|c|}
\hline & & \multicolumn{2}{|c|}{$0.05 \mathrm{~mm}$ ALA } & \multicolumn{2}{|c|}{$0.1 \mathrm{~mm}$ ALA } & \multicolumn{2}{|c|}{$0.2 \mathrm{~mm}$ ALA } \\
\hline \multirow[t]{3}{*}{ A431 } & $\begin{array}{l}\text { PplX Fluorescence (a.u.) } \\
P \text {-value (Shapiro-Wilk) }\end{array}$ & $\begin{array}{c}1479 \pm 93 \\
0.91\end{array}$ & $\begin{array}{c}1677 \pm 135 \\
0.83\end{array}$ & $\begin{array}{c}1563 \pm 109 \\
1.00\end{array}$ & $\begin{array}{c}1819 \pm 179 \\
0.035\end{array}$ & $\begin{array}{c}1642 \pm 137 \\
0.64\end{array}$ & $\begin{array}{c}1966 \pm 250 \\
0.011\end{array}$ \\
\hline & $P$-value (t-test) & \multicolumn{2}{|c|}{0.00040} & \multicolumn{2}{|c|}{-} & \multicolumn{2}{|c|}{-} \\
\hline & $P$-value (Wilcoxon) & \multicolumn{2}{|c|}{-} & \multicolumn{2}{|c|}{0.00049} & \multicolumn{2}{|c|}{0.00049} \\
\hline \multirow[t]{3}{*}{$\mathrm{FaDu}$} & $\begin{array}{l}\text { PplX fluorescence (a.u.) } \\
P \text {-value (Shapiro-Wilk) }\end{array}$ & $\begin{array}{c}1596 \pm 389 \\
0.019\end{array}$ & $\begin{array}{c}1619 \pm 406 \\
0.053\end{array}$ & $\begin{array}{c}1601 \pm 402 \\
0.079\end{array}$ & $\begin{array}{c}1780 \pm 439 \\
0.15\end{array}$ & $\begin{array}{c}1725 \pm 390 \\
0.066\end{array}$ & $\begin{array}{c}1805 \pm 378 \\
0.29\end{array}$ \\
\hline & $P$-value (t-test) & \multicolumn{2}{|c|}{-} & \multicolumn{2}{|c|}{0.31} & \multicolumn{2}{|c|}{0.61} \\
\hline & $P$-value (Wilcoxon) & \multicolumn{2}{|c|}{0.62} & \multicolumn{2}{|c|}{-} & \multicolumn{2}{|c|}{-} \\
\hline \multirow[t]{2}{*}{ SCC9 } & $\begin{array}{l}\text { PplX fluorescence (a.u.) } \\
\text { P-value (Shapiro-Wilk) }\end{array}$ & $\begin{array}{c}1714 \pm 346 \\
0.017\end{array}$ & $\begin{array}{c}2165 \pm 496 \\
0.077\end{array}$ & $\begin{array}{c}2263 \pm 587 \\
0.15\end{array}$ & $\begin{array}{c}2714 \pm 874 \\
0.078\end{array}$ & $\begin{array}{c}3115 \pm 1100 \\
0.13\end{array}$ & $\begin{array}{c}3449 \pm 1357 \\
0.039\end{array}$ \\
\hline & $P$-value (t-test) & \multicolumn{2}{|c|}{-} & \multicolumn{2}{|c|}{0.15} & \multicolumn{2}{|c|}{-} \\
\hline SCC15 & P-value (Wilcoxon) & \multicolumn{2}{|c|}{-} & \multicolumn{2}{|c|}{-} & \multicolumn{2}{|c|}{-} \\
\hline \multirow[t]{3}{*}{ SCC25 } & $\begin{array}{l}\text { PplX fluorescence (a.u.) } \\
P \text {-value (Shapiro-Wilk) }\end{array}$ & $\begin{array}{c}1496 \pm 223 \\
0.62\end{array}$ & $\begin{array}{c}2230 \pm 399 \\
0.87\end{array}$ & $\begin{array}{c}2070 \pm 526 \\
0.53\end{array}$ & $\begin{array}{c}3114 \pm 426 \\
0.74\end{array}$ & $\begin{array}{c}3368 \pm 496 \\
0.34\end{array}$ & $\begin{array}{c}3927 \pm 849 \\
0.039\end{array}$ \\
\hline & $P$-value (t-test) & \multicolumn{2}{|c|}{0.000014} & \multicolumn{2}{|c|}{0.000023} & \multicolumn{2}{|c|}{-} \\
\hline & $P$-value (Wilcoxon) & \multicolumn{2}{|c|}{-} & \multicolumn{2}{|c|}{-} & & \\
\hline
\end{tabular}

Oedema and scab formation and survival response to ALAinduced PpIX between different treatments regimen. The effect of different treatments was evaluated regarding the tumour volume on the first week after treatment where oedema was present, and the results are shown in Figure 3A. As can be seen, the fPDT had more influence in oedema formation after treatment, followed by $\mathrm{DFO}+\mathrm{fPDT}$. The presence of scab after 6 days on the treated area as an effect of tissue injury and inflammation caused by light treatment was observed for animals from all groups in the following order: $\quad \mathrm{DFO}+\mathrm{fPDT}>\mathrm{fPDT}>\mathrm{PDT}>\mathrm{DFO}+\mathrm{PDT}$ (Figure $3 \mathrm{~B}$ and $\mathrm{C}$ ).

The relative survival response of the mice regarding the treatment received was evaluated by plotting the Kaplan-Meier curves and it is presented in Figure 4A. The Kaplan-Meier curves confirmed that no significant difference in this treatment efficacy assay was observed from the administration of DFO or fPDT $\left(P_{-}\right.$ value $>0.05$, log-rank test). In this case, the heterogeneity in response between animals appeared to dwarf the magnitude of the treatment response differences between the groups.

Dosimetry analysis. Table 2 presents the results obtained for the calculated photodynamic dose, from the optical photobleaching measurements. Analysing these results, it is possible to observe that the mean of total PDT dose was the same between the groups, except for PDT alone group, which had a lower dose delivered.

In order to evaluate the effect of the absolute photodynamic dose on survival, the animals were divided in two groups with 20 animals each, one that received a low dose $(<1.0)$ and the other that received a high dose $(>1.0$; Table 2$)$. Figure $4 \mathrm{~B}$ shows a Kaplan-Meier curve, with a significant difference seen between these two groups ( $P$-value $<0.05, \log$-rank test), with mice receiving a higher photodynamic dose showing the improved treatment outcome.

\section{DISCUSSION}

This study investigated the efficacy of strategies to enhance ALAPDT treatment of skin cancer in vivo, including the use of iron chelator DFO and light fractionation (fPDT). These techniques have respectively been shown to increase PpIX level or allow PpIX and microvascular oxygen resupply. The underlying hypothesis of this study was that these effects might prove synergistic. Treatment cohorts (including PDT, DFO, fractionated and DFO + fractionated) were evaluated for both oedema and scab formation as a short-term effect and tumour regrowth as a long-term end point. Fluorescence quantification of PpIX provided insight to the total amount of photosensitizer activated (and in turn photobleached) during treatment. Interestingly, the results showed that pre-prescribed treatment strategies (e.g., DFO, fractionated and $\mathrm{DFO}+$ fractionated) did not yield significant differences in regrowth compared with non-enhanced PDT. We anticipate that the effect of DFO on PpIX accumulation occurs over a longer time period than PpIX is produced between fractions, as indicated by almost identical PpIX production before the second illumination in the fPDT and DFO + fPDT groups. This is likely the reason for the lack of any synergistic effect observed. However, the secondary end point of total photodynamic dose assessed per subject did show that it was predictive of tumour regrowth results. Thus, even though the inter-animal variability in response was high, the ability to directly measure the implicit dose from photobleaching illustrated that enhancement was feasible with the adjuvant methods.

This first steps of the present study focused on DFO enhancement of PpIX in different SCC cell lines to identify which cell lines would be the best candidates for use in vivo. The effect of ALA concentration on in vitro PpIX production was evaluated using five cell lines derived from human carcinoma 

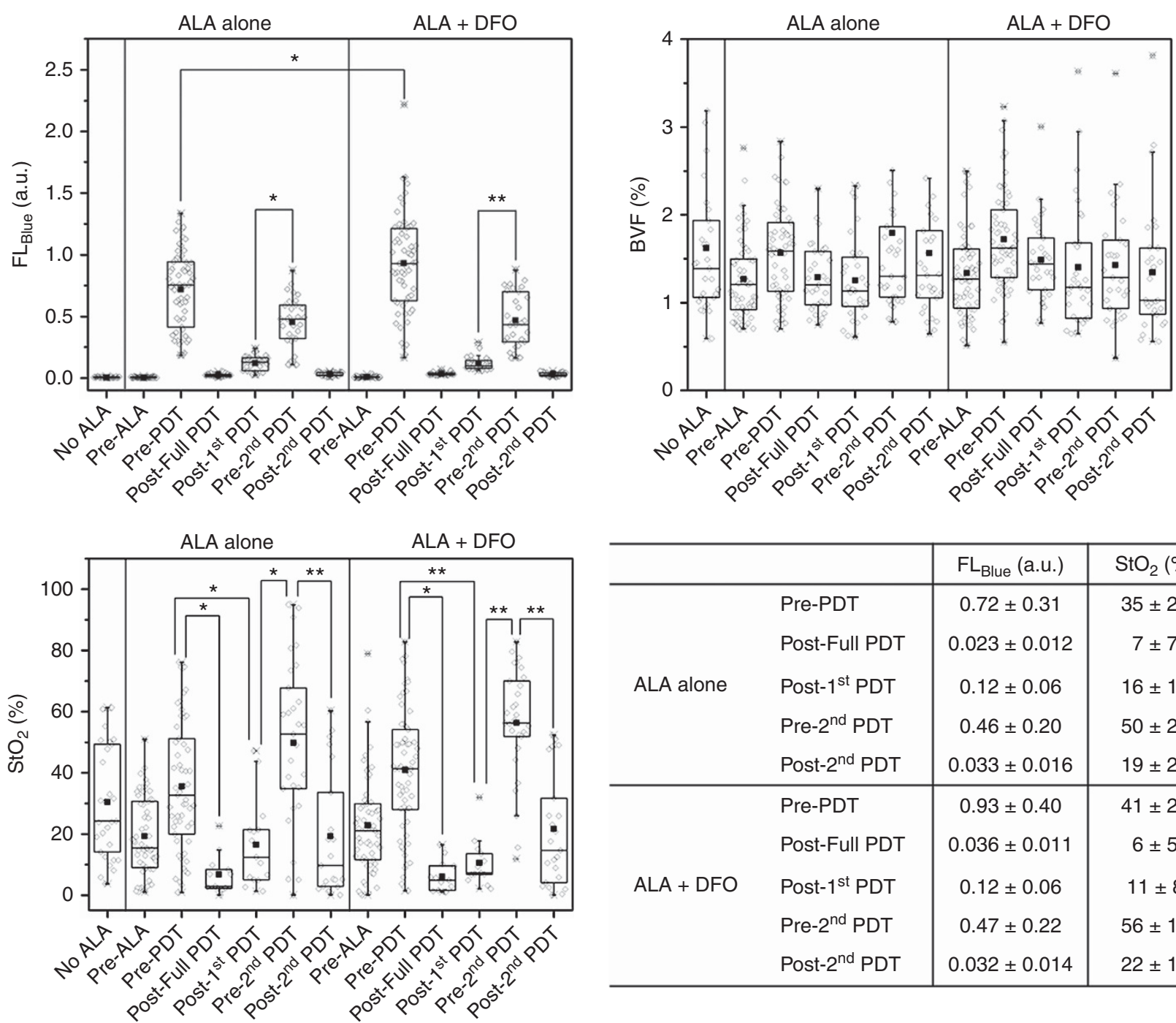

\begin{tabular}{ll|c|c}
\hline & & $\mathrm{FL}_{\text {Blue }}$ (a.u.) & $\mathrm{StO}_{2}(\%)$ \\
\hline \multirow{3}{*}{ ALA alone } & Pre-PDT & $0.72 \pm 0.31$ & $35 \pm 21$ \\
& Post-Full PDT & $0.023 \pm 0.012$ & $7 \pm 7$ \\
& Post-1 $^{\text {st }}$ PDT & $0.12 \pm 0.06$ & $16 \pm 14$ \\
& Pre-2 $^{\text {nd }}$ PDT & $0.46 \pm 0.20$ & $50 \pm 27$ \\
& Post-2 $^{\text {nd }}$ PDT & $0.033 \pm 0.016$ & $19 \pm 21$ \\
\hline \multirow{3}{*}{ ALA + DFO } & Pre-PDT & $0.93 \pm 0.40$ & $41 \pm 20$ \\
& Post-Full PDT Post- $^{\text {st }}$ PDT & $0.036 \pm 0.011$ & $6 \pm 5$ \\
& Pre-2 $^{\text {nd }}$ PDT & $0.12 \pm 0.06$ & $11 \pm 8$ \\
& Post-2 $^{\text {nd }}$ PDT & $0.032 \pm 0.014$ & $56 \pm 18$ \\
\end{tabular}

Figure 2. PpIX fluorescence measured in response to blue excitation light, and BVF and oxygen saturation determined by white light spectroscopy of skin tumours (intradermal implantation of SCC25 cells). Full-PDT meant that the animals received just one scheme illumination $3 \mathrm{~h}$ after ALA application (total fluence of $50 \mathrm{~J} \mathrm{~cm}^{-2}$ and fluence rate of $50 \mathrm{~mW} \mathrm{~cm}^{-2} ; n=10$ ). *Student's t-test, $P$-value $\leq 0.0018$. **Kruskal-Wallis test, $P$-value $\leq 0.00021$. The results in the table are presented as mean \pm s.d.

and the data showed a difference in the total amount of PpIX produced in each cell line, which is in agreement with previous studies that showed a difference in PpIX production based on the cell line used (Iinuma et al, 1994; Berg et al, 1996; Uehlinger et al, 2000). This difference could be related to the porphyrin metabolism of these cells, however, there is no correlation between the cell proliferation and PpIX production as FaDu cells proliferate much faster than SCC9, for example, and produce less PpIX. In a study performed by Iinuma et al (1994), A431 cells produced less PpIX than the other seven cell lines tested despite its high proliferation rates. The authors correlate this small production with the low activity of porphobilinogen deaminase responsible for haem biosynthesis (Iinuma et al, 1994). In another study, Berg et al (1996) showed that the difference in the maximum PpIX formation could reach 5 times depending on the cell line and the difference in $c_{\text {opt }}$ of ALA observed was 10 -fold between WiDr and V79 cells, which are cells with different growth rates. Therefore, the activity of the porphyrin enzymes is the limiting factor of PpIX production by the cells (Berg et al, 1996). Previous studies have shown that the production of PpIX can correlate with the number of mitochondria per cell, which could simply be a demonstration of high amounts of enzyme levels that are related to the number of mitochondria (Gibbs et al, 2006).

Some significant increase in ALA-induced PpIX by cells after exposure to iron chelator has been shown since the early 1990s, as a response of ferrochelatase activity inhibited due to the reduced amount of intracellular iron accessible to be incorporated into the PpIX macrocycle, converting it into haem (Hanania and Malik, 1992; Berg et al, 1996; Pye and Curnow, 2007; Blake and Curnow, 2010). Pye and Curnow (2007) demonstrated that in the absence of iron chelator, the activity of ferrochelatase is high, allowing the conversion of PpIX produced into haem. However, in the presence of CP94, an iron chelator, the activity of ferrochelatase was decreased and PpIX accumulation was seen. Here, in vitro studies of SCC demonstrated an enhancement of PpIX from DFO in four of the five cell lines, with observed increases in the range of $0-50 \%$ (Table 1). DFO most effectively increased PpIX production in SCC25 (Table 1), mainly at lower concentrations of ALA. On the basis of these results, SCC25 was the cell line chosen to be implanted in mice in order to evaluate the in vivo effect of iron chelator and/or fractionated PDT. Despite the promising results obtained with iron chelators in in vitro cell culture, there have been few studies conducted to evaluate the in vivo effects of iron chelator 

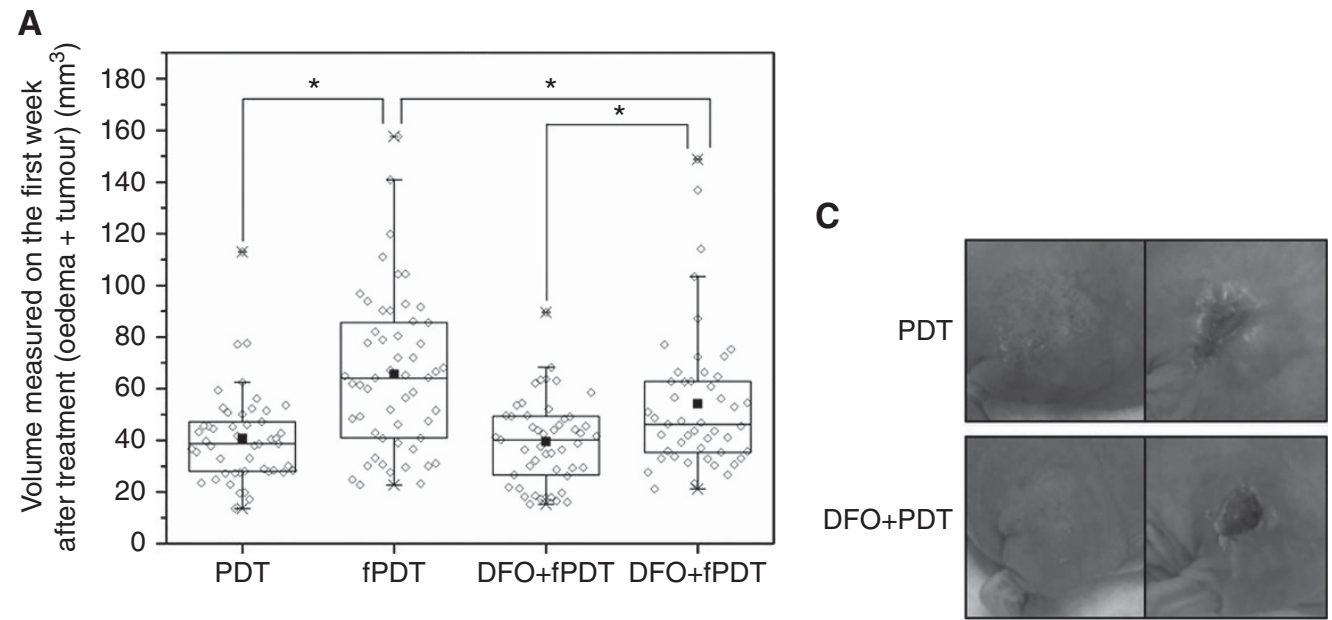

B
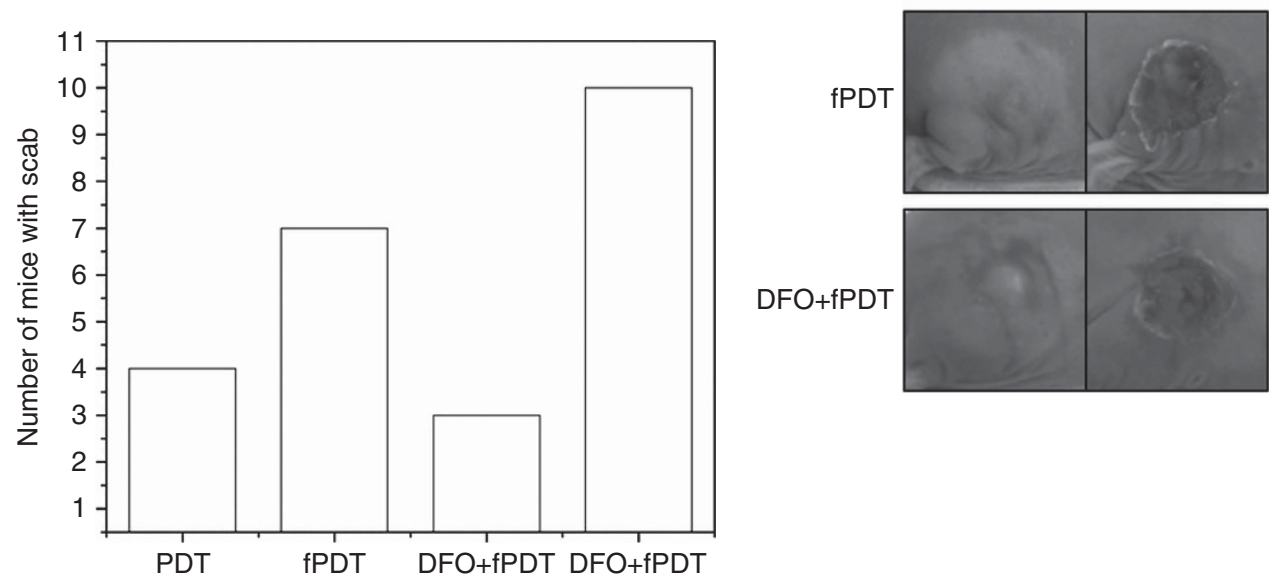

Figure 3. Treatment outcome measures. (A) A box and whisker plot of the volume measured on the first week after treatment (oedema + tumour) of skin cancer; (B) number of animals in each group that presented scab after 6 days of light treatment; (C) illustrative representation to show oedema after 1 day of treatment (left) and scab after 6 days of treatment (right). PDT groups received one scheme illumination $3 \mathrm{~h}$ after ALA application (total fluence of $50 \mathrm{~J} \mathrm{~cm}^{-2}$ ). fPDT groups received twofold illumination (total fluence of 10 and $40 \mathrm{~J} \mathrm{~cm}^{-2}, 3 \mathrm{and} 5 \mathrm{~h}$ after ALA application, respectively). ${ }^{*}$-value $<0.05$ (Kruskal-Wallis test). The samples were compared in terms of light fractionation effect (PDT/fPDT), iron chelation effect (PDT/DFO + PDT and fPDT/DFO + fPDT) or combination effect (DFO + PDT/DFO + fPDT).

Table 2. Absolute photodynamic dose and number of mice from each treatment group that received either low dose or high dose

\begin{tabular}{|c|c|c|c|c|c|}
\hline & & & & \multicolumn{2}{|c|}{ Number of mice in each group } \\
\hline Groups & $\begin{array}{l}\text { Dose_PpIX } \\
\text { (first PDT) }^{\text {a }}\end{array}$ & $\begin{array}{c}\text { Dose_PplX } \\
\text { (second PDT) }^{a}\end{array}$ & $\begin{array}{c}\text { Total } \\
\text { dose_PplX }\end{array}$ & Low dose $(<1.0)$ & High dose $(>1.0)$ \\
\hline PDT & $0.7 \pm 0.3$ & - & $0.7 \pm 0.3$ & 9 & 1 \\
\hline fPDT & $0.6 \pm 0.3$ & $0.4 \pm 0.2$ & $1.1 \pm 0.4$ & 3 & 7 \\
\hline $\mathrm{DFO}+\mathrm{PDT}$ & $1.1 \pm 0.2$ & - & $1.1 \pm 0.2$ & 3 & 7 \\
\hline
\end{tabular}

on ALA-induced PpIX in skin cancer (Choudry et al, 2003; Campbell et al, 2008).

In this study, although the difference in PpIX levels between mice that received DFO and those that did not was small $(0.93 \pm 0.40$ vs $0.72 \pm 0.31$ for animals that did not receive iron chelator as pre-treatment), it was still significant $(P$-value $<0.05$, two-sample $t$-test). This result is in contrast to a study performed by Choudry et al (2003), where no significant increase in PpIX levels was seen in tumours after addition of DFO to the ALA in the high dose clinically used. These authors associated their result obtained in vivo with the in vitro results, where an increase in PpIX production was just seen at lower concentrations of ALA. Campbell et al (2008) administered CP94 together with ALA and the results showed a significant improvement in histological tumour response with the addition of the iron chelator. Clearly the variation in impact from iron chelation is an important issue, where it can have an impact in some tumour lines and little impact in others, indicating that the value should be expected to vary across subjects. 


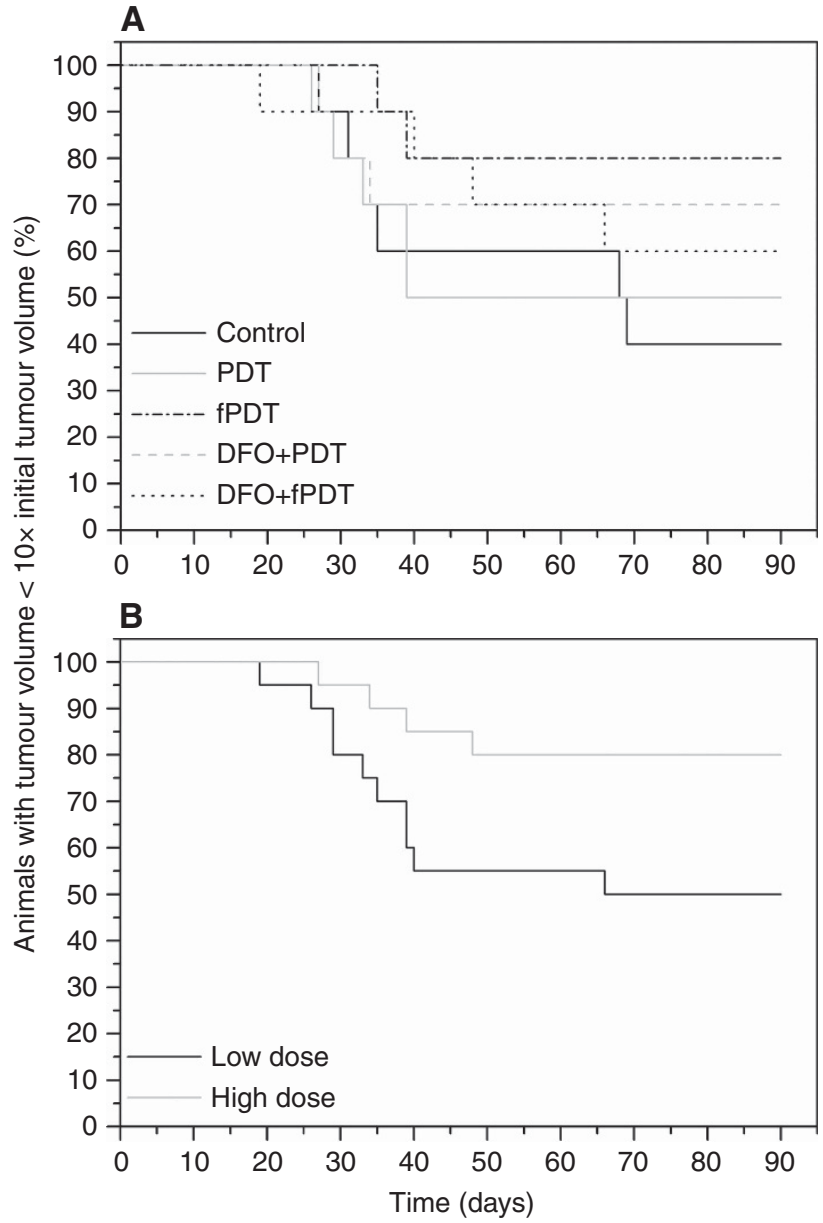

Figure 4. Kaplan-Meier curves for survival response of skin tumourbearing mice (SCC25 cells intradermal implantation). (A) Effect of treatment received ( $n=10$ animals per each group; $P$-value $=0.43$, logrank test); (B) Effect of absolute dose received ( $n=20$ animals per each group; $P$-value $=0.045$, log-rank test).

It has been extensively reported in the literature that the fractionation of light is a promising technique to improve the treatment of skin cancer and it has been used successfully in Europe as an efficient treatment for AK (Robinson et al, 2003; de Bruijn et al, 2006; de Haas et al, 2008). The high doses of PDT used in a single-illumination scheme can lead to high depletion of oxygen by photosensitizer during the photobleaching impairing the efficacy of the treatment (Foster et al, 1991; Iinuma et al, 1999).

The results of the present study show that during the 'dark' period of fractionated PDT, both PpIX and microvascular oxygen saturation were replenished. The possibility of ALA to accumulate in the skin and to be metabolised over a long period of time could explain the re-synthesis of PpIX (Malik et al, 1995; de Bruijn et al, 2007). The reestablishment of microvascular oxygen during the dark interval is of crucial importance as the efficacy of PDT is highly dependent on the tissue oxygen level and could be affected by the blood flow. However, no alteration of BVF was seen, indicating there was no lasting increase in vessel dilation. Yet interestingly the re-oxygenation process showed an over-recovery, indicating that the blood oxygen saturation was actually enhanced beyond the pre-treatment levels, presumably due to altered perfusion in the treated region. These results are in agreement with the results shown by the other authors and they are correlated to an increased response of fractionated PDT (Henning et al, 1995; Curnow et al, 2000; de Bruijn et al, 2006).
It has been described in the literature that the acute oedema after light exposure has important implications for PDT response, mainly in the treatment of cutaneous disease, as a result of vessels' permeability increased and, consequently, leakage of macromolecules and hypoxia of tissue, which is responsible for cell death. Moreover, the formation of ROS by PDT could be responsible for the damage in the endothelial cells. However, the mechanisms that produce the vascular damage are yet unknown (Fingar et al, 1992; Henderson and Dougherty, 1992; Allison et al, 2006). In vitro studies performed by Rodriguez et al (2009) using HMEC-1 microvascular endothelial cells showed that ALA was able to induce photosensitization in these cells originated from human dermal. Middelburg et al (2014) studied the in vivo PpIX production in blood vessels after the application of ALA or ALA esters (methyl and hexyl aminolevulinate) in normal skin of mice and they found that PpIX was synthesised by endothelial cells and, comparing these findings with previous results described in the literature, the authors concluded that the vascular damage has an important role in fractionated PDT efficacy; however, there is no study comparing differences in vascular damage caused by the one or twofold scheme of illumination.

The results in the present study show that the total volume of oedema + tumour during the first week after light treatment was increased in mice treated with fractionated PDT, as can be seen in Figure 3A. Moreover, the scab following 6 days of light treatment was observed in all ten animals from the DFO + fPDT group and in seven animals from the fPDT group (Figure $3 \mathrm{~B}$ and $\mathrm{C}$ ), indicating that more acute tissue damage was caused by fractionated light as compared with the single-illumination scheme. Despite this difference in reactionary response, no significant difference among treatments was observed over a longer timeline (Figure 4A), neither when the effect of iron chelator (group DFO + PDT/DFO + fPDT vs PDT/fPDT; $P$-value $=0.40$, log-rank test) nor fractionated PDT (group PDT/ $\mathrm{DFO}+\mathrm{PDT} v s \mathrm{fPDT} / \mathrm{DFO}+\mathrm{fPDT} ; P$-value $=0.29$, log-rank test $)$ were evaluated (data not shown). However, when the animals were grouped according to the absolute photodynamic dose received during the light treatment, there was significant difference in relative survival response between the animals that received a low or high dose (Figure 4B).

Thus, these results suggest that the efficacy of PDT treatment is highly correlated with the absolute photodynamic dose delivered during the light treatment. This is a promising result for the potential to improve clinical PDT applications such as measuring PDT dose, because it is relatively easy and noninvasive to use photosensitizer fluorescence in the case of skin cancers. We concluded that monitoring of the PDT dose is important to predict the efficacy of skin cancer treatment for individuals undergoing this therapy, and that some enhancement in PpIX is observed from the two potential adjuvant methods of fPDT and DFO.

\section{ACKNOWLEDGEMENTS}

This work was founded by CAPES-Proc no BEX 1376/14-4 (Brazil) and NIH research grant P01 CA084203 (USA).

\section{CONFLICT OF INTEREST}

The authors declare no conflict of interest. 


\section{REFERENCES}

Allison RR, Sibata CH, Downie GH, Cuenca RE (2006) A clinical review of PDT for cutaneous malignancies. Photodiagnosis Photodyn Ther 3: 214-226.

Anand S, Honari G, Hasan T, Elson P, Maytin EV (2009) Low-dose methotrexate enhances aminolevulinate-based photodynamic therapy in skin carcinoma cells in vitro and in vivo. Clin Cancer Res 15(10): 3333-3343.

Araújo LMPC, Thomazine JA, Lopez RFV (2010) Development of microemulsions to topically deliver 5 -aminolevulinic acid in photodynamic therapy. Eur J Pharm Biopharm 75: 48-55.

Berg K, Anholt H, Bech O, Moan J (1996) The influence of iron chelators on the accumulation of protoporphyrin IX in 5-aminolaevulinic acid-treated cells. Br J Cancer 74: 688-697.

Blake E, Curnow A (2010) The hydroxypyridinone iron chelator CP94 can enhance PpIX-induced PDT of cultured human glioma cells. Photochem Photobiol 86: 1154-1160.

Bovis MJ, Woodhams JH, Loizidou M, Scheglmann D, Bown SG, MacRobert AJ (2012) Improved in vivo delivery of $m$-THPC via pegylated liposomes for use in photodynamic therapy. J Control Release 157: 196-205.

Braathen LR, Szeimies RM, Basset-Seguin N, Bissonnette R, Foley P, Pariser D, Roelandts R, Wennberg AM, Morton CA (2007) Guidelines on the use of photodynamic therapy for nonmelanoma skin cancer: an international consensus. J Am Acad Dermatol 56: 125-143.

de Bruijn HS, Casas AG, Di Venosa G, Gandara L, Sterenborg HJ, Batlle A, Robinson DJ (2013) Light fractionated ALA-PDT enhances therapeutic efficacy in vitro; the influence of PpIX concentration and illumination parameters. Photochem Photobiol Sci 12: 241-245.

de Bruijn HS, Kruijt B, van der Ploeg-van den Heuvel A, Sterenborg HJ, Robinson DJ (2007) Increase in protoporphyrin IX after 5-aminolevulinic acid based photodynamic therapy is due to local re-synthesis. Photochem Photobiol Sci 6: 857-864.

de Bruijn HS, van der Ploeg-van den Heuvel A, Sterenborg HJ, Robinson D] (2006) Fractionated illumination after topical application of 5-aminolevulinic acid on normal skin of hairless mice: the influence of the dark interval. I Photochem Photobiol B 85: 184-190.

Cairnduff F, Stringer MR, Hudson EJ, Ash DV, Brown SB (1994) Superficial photodynamic therapy with topical 5-aminolaevulinic acid for superficial primary and secondary skin cancer. Br J Cancer 69: 605-608.

Campbell SM, Morton CA, Alyahya R, Horton S, Pye A, Curnow A (2008) Clinical investigation of the novel iron-chelating agent, CP94, to enhance topical photodynamic therapy of nodular basal cell carcinoma. $\mathrm{Br} \mathrm{J}$ Dermatol 159: 387-393.

Celli JP, Spring BQ, Rizvi I, Evans CL, Samkoe KS, Verma S, Pogue BW, Hasan T (2010) Imaging and photodynamic therapy: mechanisms, monitoring and optimization. Chem Rev 110: 2795-2838.

Chang SC, MacRobert AJ, Porter JB, Bown SG (1997) The efficacy of an iron chelator (CP94) in increasing cellular protoporphyrin IX following intravesical 5-aminolaevulinic acid administration: an in vivo study. J Photochem Photobiol B 38: 114-122.

Choudry K, Brooke RC, Farrar W, Rhodes LE (2003) The effect of an iron chelating agent on protoporphyrin IX levels and phototoxicity in topical 5-aminolaevulinic acid photodynamic therapy. Br J Dermatol 149: $124-130$.

Curnow A, Haller JC, Bown SG (2000) Oxygen monitoring during 5aminolaevulinic acid induced photodynamic therapy in normal rat colon. Comparison of continuous and fractionated light regimes. J Photochem Photobiol B 58: 149-155.

Curnow A, MacRobert AJ, Bown SG (2006) Comparing and combining light dose fractionation and iron chelation to enhance experimental photodynamic therapy with aminolevulinic acid. Lasers Surg Med 38: 325-331.

Dougherty TJ, Gomer CJ, Henderson BW, Jori G, Kessel D, Korbelik M, Moan J, Peng Q (1998) Photodynamic therapy. J Natl Cancer Inst 90: 889-905.

Fang YP, Tsai YH, Wu PC, Huang YB (2008) Comparison of 5-aminolevulinic acid-encapsulated liposome versus ethosome for skin delivery for photodynamic therapy. Int J Pharm 356: 144-152.

Fingar VH, Wieman TJ, Wiehle SA, Cerrito PB (1992) The role of microvascular damage in photodynamic therapy: the effect of treatment on vessel constriction, permeability, and leukocyte adhesion. Cancer Res 52: 4914-4921.

Foster TH, Murant RS, Bryant RG, Knox RS, Gibson SL, Hilf R (1991) Oxygen consumption and diffusion effects in photodynamic therapy. Radiat Res 126: 296-303.

Gibbs SL, Chen B, O'Hara JA, Hoopes PJ, Hasan T, Pogue BW (2006) Protoporphyrin IX level correlates with number of mitochondria, but increase in production correlates with tumor cell size. Photochem Photobiol 82: 1334-1341.

de Haas ER, Kruijt B, Sterenborg HJ, Martino Neumann HA, Robinson DJ (2006) Fractionated illumination significantly improves the response of superficial basal cell carcinoma to aminolevulinic acid photodynamic therapy. J Invest Dermatol 126: 2679-2686.

de Haas ER, de Vijlder HC, Sterenborg HJ, Neumann HA, Robinson DJ (2008) Fractionated aminolevulinic acid-photodynamic therapy provides additional evidence for the use of PDT for non-melanoma skin cancer. J Eur Acad Dermatol Venereol 22: 426-430.

Hanania J, Malik Z (1992) The effect of EDTA and serum on endogenous porphyrin accumulation and photodynamic sensitization of human K562 leukemic cells. Cancer Lett 65: 127-131.

Henderson BW, Dougherty TJ (1992) How does photodynamic therapy work? Photochem Photobiol 55: 145-157.

Henning JP, Fournier RL, Hampton JA (1995) A transient mathematical model of oxygen depletion during photodynamic therapy. Radiat Res 142: 221-226.

Ibbotson SH (2010) An overview of topical photodynamic therapy in dermatology. Photodiagnosis Photodyn Ther 7: 16-23.

Iinuma S, Farshi SS, Ortel B, Hasan T (1994) A mechanistic study of cellular photodestruction with 5-aminolaevulinic acid-induced porphyrin. $\mathrm{Br} \mathrm{J}$ Cancer 70: 21-28.

Iinuma S, Schomacker KT, Wagnieres G, Rajadhyaksha M, Bamberg M, Momma T, Hasan T (1999) In vivo fluence rate and fractionation effects on tumor response and photobleaching: photodynamic therapy with two photosensitizers in an orthotopic rat tumor model. Cancer Res 59: 6164-6170.

Kanick SC, Davis SC, Zhao Y, Sheehan KL, Hasan T, Maytin EV, Pogue BW, Chapman MS (2015) Pre-treatment protoporphyrin IX concentration in actinic keratosis lesions may be a predictive biomarker of response to aminolevulinic-acid based photodynamic therapy. Photodiagnosis Photodyn Ther 12: 561-566.

Kanick SC, Davis SC, Zhao Y, Hasan T, Maytin EV, Pogue BW, Chapman MS (2014) Dual-channel red/blue fluorescence dosimetry with broadband reflectance spectroscopic correction measures protoporphyrin IX production during photodynamic therapy of actinic keratosis. J Biomed Opt 19: 75002.

Kennedy JC, Pottier RH (1992) Endogenous protoporphyrin IX, a clinically useful photosensitizer for photodynamic therapy. J Photochem Photobiol B 14: $275-292$.

Kennedy JC, Pottier RH, Pross DC (1990) Photodynamic therapy with endogenous protoporphyrin IX: basic principles and present clinical experience. J Photochem Photobiol B 6: 143-148.

Lee CC, Pogue BW, O'Hara JA, Wilmot CM, Strawbridge RR, Burke GC, Hoopes PJ (2003) Spatial heterogeneity and temporal kinetics of photosensitizer (AlPcS2) concentration in murine tumors RIF-1 and MTG-B. Photochem Photobiol Sci 2: 145-150.

Malik Z, Kostenich G, Roitman L, Ehrenberg B, Orenstein A (1995) Topical application of 5-aminolevulinic acid, DMSO and EDTA: protoporphyrin IX accumulation in skin and tumours of mice. J Photochem Photobiol B 28 213-218.

Maytin EV, Honari G, Khachemoune A, Taylor CR, Ortel B, Pogue BW, Sznycer-Taub N, Hasan T (2012) Vitamin D combined with aminolevulinate (ALA)-mediated photodynamic therapy (PDT) for human psoriasis: a proof-of-principle study. Isr J Chem 52: 767-775.

Middelburg TA, de Vijlder HC, de Bruijn HS, van der Ploeg-van den Heuvel A, Neumann HA, de Haas ER, Robinson DJ (2014) Topical photodynamic therapy using different porphyrin precursors leads to differences in vascular photosensitization and vascular damage in normal mouse skin. Photochem Photobiol 90: 896-902.

Morton CA, MacKie RM, Whitehurst C, Moore JV, McColl JH (1998) Photodynamic therapy for basal cell carcinoma: effect of tumor thickness and duration of photosensitizer application on response. Arch Dermatol 134: $248-249$ 
Palm MD, Goldman MP (2011) Safety and efficacy comparison of blue versus red light sources for photodynamic therapy using methyl aminolevulinate in photodamaged skin. J Drugs Dermatol 10: 53-60.

Peng Q, Warloe T, Moan J, Godal A, Apricena F, Giercksky KE, Nesland JM (2001) Antitumor effect of 5-aminolevulinic acid-mediated photodynamic therapy can be enhanced by the use of a low dose of photofrin in human tumor xenografts. Cancer Res 61: 5824-5832.

Pye A, Curnow A (2007) Direct comparison of delta-aminolevulinic acid and methyl-aminolevulinate-derived protoporphyrin IX accumulations potentiated by desferrioxamine or the novel hydroxypyridinone iron chelator CP94 in cultured human cells. Photochem Photobiol 83: 766-773.

Redbord KP, Hanke CW (2007) Topical photodynamic therapy for dermatologic disorders: results and complications. J Drugs Dermatol 6: 1197-1202.

Robinson DJ, de Bruijn HS, Star WM, Sterenborg HJ (2003) Dose and timing of the first light fraction in two-fold illumination schemes for topical ALA-mediated photodynamic therapy of hairless mouse skin. Photochem Photobiol 77: 319-323.

Robinson DJ, de Bruijn HS, de Wolf WJ, Sterenborg HJ, Star WM (2000) Topical 5-aminolevulinic acid-photodynamic therapy of hairless mouse skin using two-fold illumination schemes: PpIX fluorescence kinetics, photobleaching and biological effect. Photochem Photobiol 72: 794-802.

Rodriguez L, de Bruijn HS, Di Venosa G, Mamone L, Robinson DJ, Juarranz A, Batlle A, Casas A (2009) Porphyrin synthesis from aminolevulinic acid esters in endothelial cells and its role in photodynamic therapy. J Photochem Photobiol B 96: 249-254.

Star WM, van't Veen AJ, Robinson DJ, Munte K, de Haas ER, Sterenborg HJ (2006) Topical 5-aminolevulinic acid mediated photodynamic therapy of superficial basal cell carcinoma using two light fractions with a two-hour interval: long-term follow-up. Acta Derm Venereol 86: 412-417.

Uehlinger P, Zellweger M, Wagnieres G, Juillerat-Jeanneret L, van den Bergh H, Lange N (2000) 5-Aminolevulinic acid and its derivatives: physical chemical properties and protoporphyrin IX formation in cultured cells. J Photochem Photobiol B 54: 72-80.

Valdes PA, Samkoe K, O'Hara JA, Roberts DW, Paulsen KD, Pogue BW (2010) Deferoxamine iron chelation increases delta-aminolevulinic acid induced protoporphyrin IX in xenograft glioma model. Photochem Photobiol 86: 471-475.

Di Venosa G, Fukuda H, Batlle A, MacRobert A, Casas A (2006) Photodynamic therapy: regulation of porphyrin synthesis and hydrolysis from ALA esters. J Photochem Photobiol B 83: 129-136.

This work is published under the standard license to publish agreement. After 12 months the work will become freely available and the license terms will switch to a Creative Commons AttributionNonCommercial-Share Alike 4.0 Unported License. 